\title{
ETHANOL CONSUMPTION AND INNATE NEUROIMMUNITY
}

\author{
Stefania Ciafrè̀ ${ }^{1,2}$,Valentina Carito ${ }^{2}$, Paola Tirassa ${ }^{2}$, Giampiero Ferraguti ${ }^{3}$, Maria Luisa Attilia ${ }^{4}$, \\ Paola Ciolli ${ }^{5}$, Marisa Patrizia Messina ${ }^{4}$, Mauro Ceccanti ${ }^{4}$, and Marco Fiore ${ }^{2 *}$ \\ ${ }^{1}$ Institute of Translational Pharmacology, CNR, Rome, Italy \\ ${ }^{2}$ Institute of Cell Biology and Neurobiology, IBCN-CNR, Rome, Italy \\ ${ }^{3}$ Department of Cellular Biotechnologies and Hematology, Sapienza University, Rome, Italy \\ ${ }^{4}$ Centro Riferimento Alcologico Regione Lazio, Sapienza University, Rome, Italy \\ ${ }^{5}$ Department of Gynecology and Obstetric, and Urology, Sapienza University, Rome, Italy
}

\begin{abstract}
Emerging researches from human and animal models have shown the role of ethanol in innate immune system modulation, particularly in the central nervous system. The activation of receptors of the innate immunity, Toll-like receptors and nucleotide-binding oligomerization domain-like (NOD-like) receptors, triggers the signaling pathways that bring to the production of pro-inflammatory cytokines and chemokines, which, in turn, provokes neuroinflammation and neural damage. The neuroimmune system response to ethanol intake, in specific brain regions such as amygdala, hippocampus and frontal cortex, is involved in addiction and in behavioural deficits observed in alcoholism. In murine models, the knockout for Toll-like or NODlike receptors abolishes most of the effects of ethanol on the immune system and preserves these mice from neural damage, neuroinflammation and alcohol dependence. Molecular targeting of immune system pathways is a new and promising area of research for the discovery of new biomarkers for neuroinflammation and for the development of novel pharmacotherapies in order to treat neurological and behavioural consequences of ethanol addiction. Biomed Rev 2017; 28: 49-61.
\end{abstract}

Keywords: ethanol addiction, neuroinflammation, neuroimmunity, Toll-like receptors, NOD-like receptors, inflammasomes

\section{INTRODUCTION}

Ethanol modifies the immune inflammatory signals in the central nervous system (CNS) as well as in the rest of the body, so the immune system is strongly modulated by alcohol intake $(1,2)$. Alcohol consumption may disrupt tight junctions in gut epithelium, allowing the bacterial lipopolysaccharides (LPS), part of the external membrane of the Gram-negative bacteria, to leak from the gut, where they are usually confined, and pass into the blood stream (3, 4). Lipopolysaccharides (also termed endotoxin) activates the immune receptor 4 in liver Kupffer cells promoting an alcohol-induced liver inflammation enhanced by immune cells; monocytes, macrophages, $\mathrm{T}$ lymphocytes and dendritic cells are stimulated to secrete pro-inflammatory cytokines such as interleukins (IL), IL-1b, IL-6 and tumor necrosis factor-alpha (TNF- $\alpha$ ) (1). Indeed, this pro-inflammatory cascade (5), induced by alcohol in the periphery, stimulates both the adaptive and the innate immune system $(3,6)$. Lymphocytic cells that specifically recognize and memorize invading pathogens, producing antibodies, constitute the adaptive immune system that creates the immunological memory to defend the organism from future infections. Instead, in innate immunity, pathogens trigger a non-specific immune response that, secreting

Received 24 November 2017, accepted 8 December 2017

* Correspondence and reprint request to Dr Marco Fiore, Institute of Cell Biology and Neurobiology, IBCN-CNR, Via del Fosso di Fiorano 64, 00143 Roma, Italy

Phone: +39 06501703 239, Fax +3906 501703 313, E-mail: marco.fiore@cnr.it 
pro-inflammatory cytokines and chemokines stimulate CNS neuroimmune cells (microglia and astrocytes) to further produce cytokines (7).

Pro-inflammatory cytokines may use different routes to access the brain: via afferent vagal fibres (8), through leaky regions of the blood-brain barrier (area postrema), by active cytokine-specific transporter or through second messenger molecules of CNS endothelia $(9,10)$.

\section{THE ACTIVE IMMUNE DEFENCE IN THE CNS: MICROGLIA AND ASTROCYTES}

Microglia, a type of glial cells in the CNS and spinal cord, actively manages immune defence in CNS; along with the resident macrophages and astrocytes, microglia recognizes and destroys infectious agents and prevents the damage to the neural tissue (11-13). Microglia cells also control the overall brain homeostasis, as they continuously scavenge the CNS looking for damaged neuron cells and pathogens (12). The multiplicity of microglia functions are made possible by their exceptional plasticity, these cells can change their morphology and phenotype to respond to local chemical signals (14, 15). In absence of pathogens or dying cells microglia adopt the "resting form" that consists in a small cellular body with long branching processes, that constantly scan the surrounding area to sense even small changes in physiological conditions $(16,17)$.

When microglia detects an endogenous or exogenous insult, it becomes activated and undergoes changes in morphology and gene expression through a response gradient that goes from a ramified form to a totally active phagocytic form $(18,19)$. In this state, microglia quickly uptakes the major histocompatibility complex (MHC) class I/II proteins and becomes an efficient antigen presenter for T-cell activation. Also in this form these cells can destroy foreign materials and interact with astrocytes, other components of neuroimmune system able to secrete cytokines after activation $(20,21)$.

\section{THE TOLL-LIKE RECEPTOR SYSTEM}

Lipopolysaccharides as well as other microbe-derived evolutionarily conserved molecules are recognized by the innate immune Toll-like receptors (TLR; from 1995 Nobel Prize winner Christiane Nüsslein-Volhard's 1985 exclamation Das ist ja Toll - that's great/amazing). The TLRs belong to an evolutionary conserved family of receptors involved in the protection against microbial infections (22). The family of these receptors includes 11 members (TLR1-11) in humans, the most studied of which is TLR4. This kind of receptors are pattern recognition receptors (PRRs) that identify the pathogen-associated molecular pattern (PAMPs) and molecular signatures of different classes of bacteria (23). The cytoplasmic nucleotide binding domain leucine-rich repeat containing receptors (known as NLRs or nucleotide-binding oligomerization domain-like receptors, in brief NOD-like receptors) can also activate an innate immune response, recognizing circulating pathogens. Both, cytoplasmic NLRs and membrane TLRs react not only to pathogens but also to hostcell derived molecules, called damage-associated molecular patterns (DAMPs, danger signals, or alarmins), which are generic markers for damage (24). Among them, there are the IL-33 and the High-Mobility Group Box 1 (HMGB1) proteins, which, when activated, become hyperacetylated on lysine residues, translocate from nucleus to cytosol where bind to different receptors and finally activate the nuclear factor kappa-light-chain-enhancer of activated B cells (NF-kB) (25, 26). The role of alarmins in eliciting the "sterile inflammation" without the presence of pathogens is crucial in the CNS neurodegenerative diseases (27).

\section{INTERACTION BETWEEN ETHANOL AND THE IMMUNE RESPONSE}

The first demonstration that ethanol can activate the immune signalling pathway and the synthesis of pro-inflammatory cytokines in the brain was obtained by experimental studies of Valles (28). The up-regulation of NF-kB and the expression of pro-inflammatory proteins induced by ethanol was observed in vitro in rat brain slices (29) and in primary cultured astroglial and microglial cells $(30,31)$. Ethanol can modulate the signalling of different immunoreceptors, the most studied are TLR4 and NLRP3 (NACHT, LRR and PYD domains-containing protein 3). The link between them is the activation of NF-kB (32). The receptor signalling associates with its internalization and trafficking (33) and through the activation of MAPK and transcription factors such as NF-kB or AP-1. The subsequent production of cytokines such as pro-IL-1 $\beta$, IL-6, IL-8 and TNF- $\alpha$, chemokines, like the monocyte chemoattractant protein-1 (MCP-1), and inflammatory mediators such as inducible nitric oxide synthase (iNOS) and cyclooxygenase-2 (COX-2), leads, finally, to neuroinflammation $(30,31,34)$.

The activation of receptor signalling starts with a "priming signal" of TLR4 that generates, via induction of NF-kB, the synthesis of pro-IL-1 $\beta$. This signal, along with reactive 
oxygen species (ROS) production, elicited by the action of ethanol on mitochondria, generates a second signal that activates the formation of a big multiprotein complex called inflammasomes that mediates the activation of caspase- 1 that, in turn, produces and releases the mature form of IL-1 $\beta$ (35). The crucial role of TLR4 in inflammatory response and glial activation induced by ethanol was confirmed in vitro using siRNA. Interference against TLR4 abolished inflammatory response in vivo, in mice models of chronic ethanol intake, and in vitro, in cultured glial cells or in glial cells from TLR4 knockout mice $(34,35)$. In these models, TLR4 knockout mice resulted to be protected from neuroinflammation, myelin disruption and apoptosis in cerebral cortex, mediated by induction of MAPK and NF-kB (36-40).

Alcohol also impairs the pathways of ubiquitin-proteasome and autophagy-lysosome: ubiquitinated proteins accumulate contributing to brain damage and neurodegeneration (41). The activation of TLR4/NLRP3 inflammasomes promotes leukocyte infiltration, compromises the blood-brainbarrier integrity (40) and inhibits hippocampal neurogenesis (42). The high levels of cytokines induced by ethanol remain in the brain for a long period after alcohol exposure whereas in periphery cytokines return more rapidly to normal levels (29). This long-term effect of ethanol in the neuroimmune system was also observed in animals exposed to alcohol in adolescence $(43,44)$ and in postmortem alcoholic brain $(45$, 46), where, in addition, blood-brain-barrier integrity alterations have been found (47). Moreover, ethanol induces activation (through acetylation) and extracellular release of HMGB1, its pro-inflammatory action is mediated by the activation of TLR4. Ethanol promotes also the expression of NLRP3 in neurons and in astrocytes; the increased expression in these cells was also observed in post-mortem alcoholic brains.

\section{ACUTE AND CHRONIC ETHANOL CONSUMPTION EFFECTS}

The immunomodulatory regulation of ethanol produces opposite effects depending on acute or chronic alcohol drinking (5), but the exact molecular mechanism behind this effect is still unclear. In animal models exposed to a pathogen, acute alcohol administration decreases the levels of IL-6, TNF- $\alpha$ and IL-1 $\beta$ (48). LPS stimulated human monocytes or binge drinking animal models have shown that acute alcohol administration induces TLR4/LPS tolerance, which develops through the up-regulation of the nuclear protein Bcl-3 that binds to the p50 subunit of the nuclear factor NF-kB (32A).
This binding blocks the transcription of NF-kB regulated genes, that include pro-inflammatory cytokines (49), while stimulates the transcription (50) of apoptotic genes (51). In contrast, chronic ethanol exposure converts the anti-inflammatory response to pro-inflammatory through NF-kB activation and TNF- $\alpha$ induction $(50,52,53)$.

While the immune response to ethanol is a sex-independent event, the extent of neuroinflammation, the levels of inflammatory markers such as iNOS and COX-2, the neuronal loss and the activation of caspase- 1 are much more pronounced in females (38).

\section{HYPOTHALAMIC-PITUITARY-ADRENAL-AXIS (HPA)}

Dysregulation of HPA and imbalance of glucocorticoid receptor are commonly observed during alcohol administration; the severity of these effects depends on the stage of alcoholism and on the ethanol dose (54). In chronic ethanol intake, basal adrenocorticotropic hormone (ACTH) levels are elevated and the stress-induced release of cortisol and corticotrophins is inhibited (55). During withdrawal, the negative behavioural effects and the dysphoric symptoms such as tremor, anxiety and agitation arise from an immune-mediated activation of brain stress circuitry, because of the inflammatory cytokines that are strong inducers of the hypothalamic corticotrophinreleasing factor $(\mathrm{CRF})(56,57)$.

Glucocorticoids produced by inflammatory cytokines dysregulate the catabolic pathway of tryptophan, the serotonin precursor, activating two different enzymes: the hepatic tryptophan 2,3-dioxygenase (TDO) $(58,59)$ and indolamine 2,3 dioxygenase (IDO) in the brain. Both of them degrade tryptophan along the neurotoxic kynurenine pathway $(60,61)$. The activation of this metabolic pathway causes a depletion of serotonin, while the production of metabolites of kynurenine such as anthranilic and quinolinic acid by brain microglia, that acts as NMDA receptor agonists, causes neurotoxic effects (62). Dysregulation of tryptophan metabolism lasts for a long period during abstinence and induces physiological responses with mood disorders and emotional and behavioural lability, traits in common with depressive disorders (63-65).

\section{NEUROIMMUNE SIGNALLING IN ADDICTION AND ALCOHOL DRINKING}

Many pieces of evidence have shown that ethanol-induced neuroimmune signalling is involved in the progression of addiction (66). The alcohol-dependent alteration of the limbic system and frontal cortex imbalances long-term po- 
tentiation and long-term depression and reduces neuronal plasticity; particularly, binge drinking is followed by a long term default in learning, $(67,68)$ emotive response and memory, typical of alcoholism (7, 67-70) (Fig. 1).

Zou and Crews, using an ex vivo model of organotypic hippocampal-entorhinal cortex brain slice culture, showed that 4 days of treatment with $100 \mathrm{mM}$ ethanol decreased neurogenesis, cellular proliferation (73) and caused an im- balance of neuroimmune/neurotrophic factors. Augmented pro-inflammatory cytokine IL-1 $\beta$ increased the expression of cAMP response element binding protein (CREB), involved in the activation of many different transcription factors, while brain-derived neurotrophic factor (BDNF) levels were reduced. The blocking of IL-1 $\beta$ with a neutralizing antibody or administration of inhibitors of NF-kB reversed the ethanol-induced inhibition of neurogenesis. Neurogen-

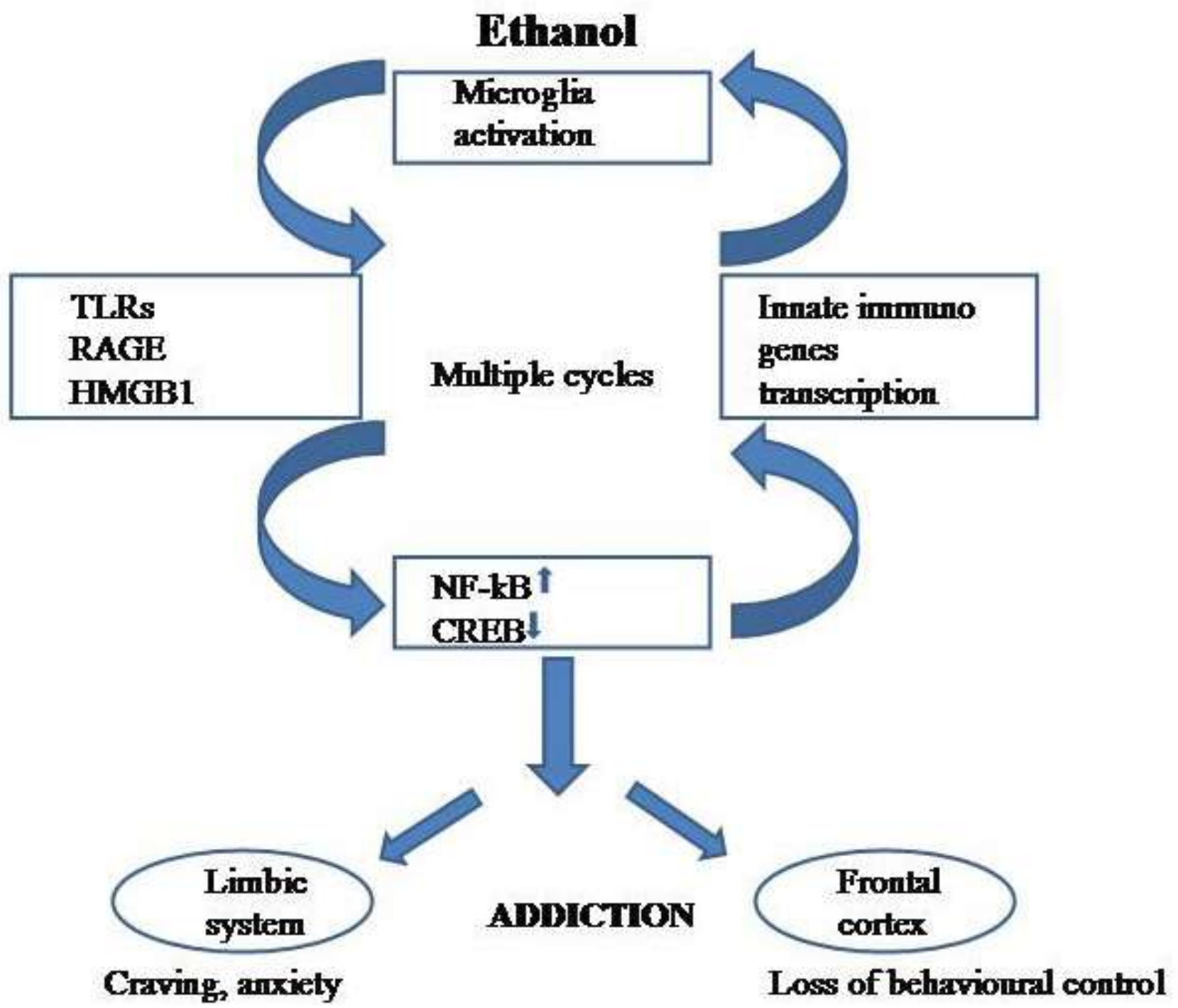

Figure 1. Neuroimmune molecular pathway in addiction.

The alcohol-mediated stimulation of microglia and astrocytes in the central nervous system activates the neuroimmune receptors TLRs and RAGE and the alarmin HMGB1. This alcohol-mediated stimulation of microglia and astrocytes downregulates $C R E B$ and increases the expression of $N F-k B$ that in turn activates the transcription of innate immune genes. This pathway produces multiple cycles of neuroimmune gene activation which lead to amplification and spreading of neuroinflammation causing neuronal cell death and up-regulation of the limbic system circuitry. This neuroimmune gene activation elicits also negative effects on anxiety and craving, frontal cortex down-regulation with changes in impulsivity, progressive loss of attention and reduced decision making. All these behavioural modifications culminate in addiction (adapted from 45, 66). 
esis and hippocampal stem cells proliferation were also impaired in vivo models of chronic binge drinking (74). Anti-depressive treatment reversed the depression-like behaviour and the inhibition of neurogenesis $(71,73)$.

Chronic alcohol intake determines a permanent activation of microglia and astrocytes (74) that, at the end, results in neuronal damage and cell death (28). Interestingly, in a murine model, administration of prednisone, a synthetic glucocorticoid, was found to increase anxiety-like behaviour and to induce microglial proliferation in frontal cortex and hippocampus (77). These evidences that represent a link between neuroimmune signalling, endocrine system and behavioural alterations, can be at the basis of novel strategies for the treatment of addictions. Moreover, knockout mice models demonstrated that modulation of alcohol intake relies on TLRs/NLRSs signalling. TLR4 knockout mice are preserved from up-regulation of brain cytokines and chemokines, do not show cognitive dysfunction or anxiety during withdrawal (after chronic ethanol administration) and manifest a less marked preference for alcohol intake $(33,78-81)$. Similar results were obtained in knockout mice models for immunorelated genes coding for proteins produced by microglia and astrocytes (82). Recent studies in murine models, employing the infusion in vivo of siRNA vectors targeting TLR4/MCP-1 in specific brain regions such as central nucleus of the amygdala or ventral tegmental area, demonstrated that the block of this signalling blunted binge drinking (79). Moreover, a protein crosstalk between TLR4 and CRF was described: alcohol drinking increases the expression of CRF that, in turn, exert a feedback regulation on TLR4/MCP-1 signalling, this mechanism can potentially contribute to the switch to alcohol dependence (79).

\section{CYTOKINES AS BIOMARKERS}

The clinical diagnosis of alcoholism needs the development of reliable biomarkers that can be indicators of alcohol use and abuse. An emerging research area concerns the use of plasma or serum cytokine levels as potential biomarkers of alcoholism and alcohol-induced tissue damage (83). To increase sensibility and specificity, serum and plasma levels of cytokines may be tested together with other markers already in use: ethyl glucuronide $(\mathrm{EtG})(84,85)$, gamma-glutamyltransferase (GGT) (86), alanine aminotrasferase (ALT), aspartate aminotransferase (AST) (87), mean corpuscular volume (MCV) (88), carbohydrate-deficient trasferrin (CDT)
(89), 5-hydroxytryptophol (5HTOL) (90), phosphatidylethanol (PEth) (89).

In neurological diseases like Alzheimer's (AD) and Parkinson's diseases high levels of inflammatory cytokines were observed. Björkqvist and colleagues identified a panel of plasma proteins, including cytokines, which enabled the accurate diagnosis of AD with an accuracy of $90 \%$ (92). The development of biomarkers panels (cytokines) as a signature of neurological disease may provide a strong rationale to extend this strategy to alcohol abuse, considering that alcoholism also causes neuroinflammation and neurodegeneration (75). Indeed, TNF- $\alpha$ IL-1 and IL- 6 were found to be elevated in both chronic and acute alcohol-induced liver disease (93) and TNF- $\alpha$ levels were higher in hospitalized alcoholics than in general population $(94,95)$. These higher levels of circulating cytokines, which correlate with liver dysfunction, were also present in alcoholics without liver disease. A biomarker panel, comprehensive of other circulating proteins such as growth factors, could improve sensibility of alcohol abuse testing (96-107). Studies on pregnant women consuming alcohol have shown a profound effect of ethanol intake on the concentration of circulating epidermal growth factor and placental growth factor (108). Recent studies have also shown the role of small non coding RNAs as modulators of neuroinflammation and as potential bio-markers in addiction and neurological diseases $(109,110)$ : miR-155 in cerebellum, that is TLR4-dependent and up-regulates TNF- $\alpha$ and MCP-1 levels, is modified by chronic alcohol abuse (111); miR339$5 p$ inhibits neuroinflammation and regulates NF-kB signalling (112).

\section{NEUROIMMUNE SYSTEM AND BINGE DRINKING}

Studies in animal models confirm that occasional and repeated episodes of binge drinking, a common way of drinking alcohol in adolescence, induce modifications in the hippocampus and brain cortex $(113,114)$, dysfunction of neurogenesis (45) and disorganization in synapses and myelin (80). During adolescence, the still growing brain performs structural and functional remodelling of neural pathway in regions such as cortex, amygdala, hippocampus and nucleus accumbens $(115,116)$. These regions are crucial for a normal brain maturation from childhood to adulthood (117). The synaptic remodelling during the adolescence, coupled to an increased sensitivity to alcohol toxicity, impairs selfcontrol and goal setting behaviours and can bring to cognitive and behavioural deficits $(43,44,80,119)$ and to a later 
development of alcohol dependence (118).

Binge drinking activates the neuroimmune system cells microglia and astrocytes. The release of pro-inflammatory cytokines, chemokines and ROS causes neuroinflammation and neuronal death (120-122). Binge-like ethanol administration in adolescent rats up-regulates TLRs, receptor for advanced glycation end products (RAGE), HMGB1, TNF- $\alpha$ and IL-1 $\beta$ mRNA in the prefrontal cortex and activates microglia; this activation lasts for a long period after alcohol consumption $(6,33,123)$. Damaged neurons release HMGB1 that activates TLR4, RAGE and the signalling pathway that produces cytokines (124). Interestingly, chronic ethanol exposure has been proven to promote the neuronal release of HMGB1, presumably trough a decrease in HDAC activity, mediating this way the pro-inflammatory effects of ethanol (124). Other works have shown that mitochondrial ROS produced by ethanol activates TLR4/NLRs response in microglia stimulating $\operatorname{HMGB} 1$ release $(35,40)$. The stability and persistence of HMGB1 secretion define its role of an enduring activator of inflammation damage (113).

In a rat model, maternal binge drinking during gestation and lactation caused motor coordination impairments during the rotarod test and $\mathrm{Y}$ maze performance disruptions in adult male offspring (125), supposedly linked to up-regulation of pro-inflammatory signalling (TLR4, NF-kB p65, NLR protein3, caspase 1 , and IL-1 $\beta$ ). Moreover, neuronal loss and down-regulation of structural myelin proteins in prefrontal cortex and hippocampus (125) were also observed. The consequent neuroinflammation might be responsible for the worsening of behavioural deficits observed in fetal alcohol spectrum disorders (FASD). In a rat model of adolescent mice wild-type and knockout for TLR4, Montesinos and colleagues showed that binge-like ethanol drinking promoted the up-regulation of BDNF and FosB genes (through epigenetic changes in the promoter regions) in the medial prefrontal cortex. In these young animals, long-term rewarding and anxiogenic effects that increase alcohol preference were observed, while TLR4-knockout mice were protected from these alterations (43).

\section{PHARMACOLOGICAL APPROACHES MODULATING NEUROIMMUNE SYSTEM ACTIVATION}

The involvement of neuroimmune system in alcohol consumption and dependence and its role in neurological damage associated with ethanol abuse have encouraged the development of pharmacological treatments in an attempt to normal- ize the immune signalling. The aims are to control the short and long-terms' effects of ethanol intake in adulthood and in adolescence and to fine-tune a more effective immune-based pharmacotherapy. Many anti-inflammatory compounds that treat the neural damage induced by alcohol and reduce microglia activation are under observation. Minocyclines, for example, inhibit microglia activation and reduce ethanol intake in a 2-bottle choice voluntary drinking model (126). Anakinra, an antagonist of IL-1 receptor, blocks the activation of NLRP3 and reduces alcohol-induced sedation in mice models $(111,127)$. Nonsteroidal anti-inflammatory substances, such as indomethacin, an inhibitor of COX-2, reduces neuroinflammation and behavioural deficits in a binge drinking model of rats receiving alcohol in adolescence (121). Antagonists that blocks the over-expression of HMGB1, such as glycyrrhizin or ethyl pyruvate, avoid the brain damage induced by chronic alcohol consumption (128). Recently, it was shown that oleoylethanolamide, a compound with anti-inflammatory and neuroprotective properties, was able to stop the neuroimmune signalling in the rat frontal cortex and to improve the behavioural deficits induced by ethanol binge administration (129).

\section{CONCLUSIONS AND PERSPECTIVES}

The complex pathology of alcoholism strongly depends on genetic, epigenetic and environmental factors. A deeper knowledge is needed to understand the global pattern of cellular and molecular mechanisms related to alcoholism and to unravel the role of other proteins such as growth factors and adipokines (adipose tissue-derived signaling proteins). In addition, the influence of other components such as life style, nutrition, aging and gender differences need to be further investigated. Polyphenols are a family of compounds consistently present in the human diet. There are different types of polyphenols like tannins, flavonoids and resveratrol. Polyphenols can counteract inflammation because of their action on transcription factors and their inhibitory effect on NF-kB signalling. Many polyphenols have been studied for their anti-inflammatory and/or antioxidant properties and for their role in regulating neurotrophins levels (130). Their potential therapeutic application against inflammation and oxidative imbalance extends to a large number of conditions affecting different organs, brain included (131). A better comprehension of the protective effect provided by polyphenols might be of primary interest for drug discovery and diet-based prevention of the neuroinflammatory insults associated with 
chronic alcohol abuse.

\section{CONFLICT OF INTEREST STATEMENT}

The authors certify that they have no affiliations with or involvement in any organization with any financial interest in the subject matter discussed in the present review.

\section{REFERENCES}

1. Crews FT, Vetreno RP. Mechanisms of neuroimmune gene induction in alcoholism. Psychopharmacology (Berl) 2016;233:1543-1557. DOI:10.1007/s00213-0153906-1

2. Szabo G, Saha B. Alcohol's effect on host defense. Alcohol Res Curr Rev 2015;37:159-170.

3. Mandrekar P, Szabo G. Signalling pathways in alcoholinduced liver inflammation. J Hepatol 2009;50:12581266. DOI:10.1016/j.jhep.2009.03.007

4. Ferrier L, Bérard F, Debrauwer L, Chabo C, Langella P, Buéno L, et al. Impairment of the intestinal barrier by ethanol involves enteric microflora and mast cell activation in rodents. Am J Pathol 2006;168:1148-1154. DOI:10.2353/ajpath.2006.050617

5. Szabo G, Mandrekar P. A recent perspective on alcohol, immunity, and host defense. Alcohol Clin Exp Res 2009;33:220-232. DOI:10.1111/j.15300277.2008.00842.x

6. Vetreno RP, Qin L, Crews FT. Increased receptor for advanced glycation end product expression in the human alcoholic prefrontal cortex is linked to adolescent drinking. Neurobiol Dis 2013;59:52-62. DOI:10.1016/j. nbd.2013.07.002

7. Dantzer R, O'Connor JC, Freund GG, Johnson RW, Kelley KW. From inflammation to sickness and depression: when the immune system subjugates the brain. Nat Rev Neurosci 2008;9:46-56. DOI:10.1038/nrn2297

8. Watkins LR, Maier SF, Goehler LE. Cytokine-to-brain communication: a review \& analysis of alternative mechanisms. Life Sci 1995;57:1011-1026. DOI: 10.1016/00243205(95)02047-M

9. Banks WA, Erickson MA. The blood-brain barrier and immune function and dysfunction. Neurobiol Dis 2010;37:26-32. DOI:10.1016/j.nbd.2009.07.031

10. Qin L, Wu X, Block ML, Liu Y, Breese GR, Hong J-S, et al. Systemic LPS causes chronic neuroinflammation and progressive neurodegeneration. Glia 2007;55:453-62. DOI:10.1002/glia.20467
11. Kreutzberg GW. Microglia, the first line of defence in brain pathologies. Arzneimittelforschung 1995;45:35760.

12. Gehrmann J, Matsumoto Y, Kreutzberg GW. Microglia: intrinsic immuneffector cell of the brain. Brain Res Brain Res Rev 1995;20:269-87. [DOI: 10.1016/01650173(94)00015-H]

13. Davis EJ, Foster TD, Thomas WE. Cellular forms and functions of brain microglia. Brain Res Bull 1994;34:7378. DOI:10.1016/0361-9230(94)90189-9]

14. Rock RB, Gekker G, Hu S, Sheng WS, Cheeran M, Lokensgard JR, et al. Role of microglia in central nervous system infections. Clin Microbiol Rev 2004;17:942-964, table of contents. DOI:10.1128/CMR.17.4.942-964.2004

15. Eggen BJL, Raj D, Hanisch U-K, Boddeke HWGM. Microglial phenotype and adaptation. $J$ Neuroimmune Pharmacol 2013;8:807-823. DOI:10.1007/s11481-013-94904

16. Ferrer I, Bernet E, Soriano E, del Rio T, Fonseca M. Naturally occurring cell death in the cerebral cortex of the rat and removal of dead cells by transitory phagocytes. Neuroscience 1990;39:451-458.

17. Aloisi F. Immune function of microglia. Glia 2001;36:165-79. [DOI: 10.1002/glia.1106]

18. Graeber MB, Streit WJ. Microglia: biology and pathology. Acta Neuropathol (Berl) 2010;119:89-105. DOI:10.1007/s00401-009-0622-0

19. Graeber MB. Changing face of microglia. Science 2010;330:783-8. DOI:10.1126/science.1190929

20. Aschner M, Sonnewald U, Tan KH. Astrocyte modulation of neurotoxic injury. Brain Pathol Zurich Switz 2002;12:475-481. DOI: 10.1111/j.1750-3639.2002. tb00465.x

21. Aschner M. Astrocytes as mediators of immune and inflammatory responses in the CNS. Neurotoxicology 1998;19:269-281.

22. Medzhitov R, Preston-Hurlburt P, Janeway CA. A human homologue of the Drosophila Toll protein signals activation of adaptive immunity. Nature 1997;388:394-397. DOI:10.1038/41131

23. Akira S, Takeda K, Kaisho T. Toll-like receptors: critical proteins linking innate and acquired immunity. Nat Immunol 2001;2:675-680. DOI:10.1038/90609

24. Bianchi ME. DAMPs, PAMPs and alarmins: all we need to know about danger. J Leukoc Biol 2007;81:1-5. DOI:10.1189/jlb.0306164

25. Ibrahim ZA, Armour CL, Phipps S, Sukkar MB. RAGE 
and TLRs: relatives, friends or neighbours? Mol Immunol 2013;56:739-744. DOI:10.1016/j.molimm.2013.07.008

26. El Mezayen R, El Gazzar M, Seeds MC, McCall CE, Dreskin SC, Nicolls MR. Endogenous signals released from necrotic cells augment inflammatory responses to bacterial endotoxin. Immunol Lett 2007;111:36-44. DOI:10.1016/j.imlet.2007.04.011

27. Glass CK, Saijo K, Winner B, Marchetto MC, Gage FH. Mechanisms underlying inflammation in neurodegeneration. Cell 2010;140:918-934. DOI:10.1016/j. cell.2010.02.016

28. Vallés SL, Blanco AM, Pascual M, Guerri C. Chronic ethanol treatment enhances inflammatory mediators and cell death in the brain and in astrocytes. Brain Pathol Zurich Switz 2004;14:365-371. DOI: 10.1111/j.17503639.2004.tb00079.x

29. Qin L, He J, Hanes RN, Pluzarev O, Hong J-S, Crews FT. Increased systemic and brain cytokine production and neuroinflammation by endotoxin following ethanol treatment. J Neuroinflam 2008;5:10. DOI:10.1186/17422094-5-10

30. Blanco AM, Vallés SL, Pascual M, Guerri C. Involvement of TLR4/type I IL-1 receptor signaling in the induction of inflammatory mediators and cell death induced by ethanol in cultured astrocytes. J Immunol 2005;175:68936899. DOI:10.4049/jimmunol.175.10.6893

31. Blanco AM, Perez-Arago A, Fernandez-Lizarbe S, Guerri C. Ethanol mimics ligand-mediated activation and endocytosis of IL-1RI/TLR4 receptors via lipid rafts caveolae in astroglial cells. $J$ Neurochem 2008;106:625-639. DOI:10.1111/j.1471-4159.2008.05425.X

32. Guo S, Yang C, Diao B, Huang X, Jin M, Chen L, et al. The NLRP3 Inflammasome and IL-1 $\beta$ Accelerate Immunologically Mediated Pathology in Experimental Viral Fulminant Hepatitis. PLoS 2015;11:e1005155. DOI:10.1371/journal.ppat.1005155

33. Pascual-Lucas M, Fernandez-Lizarbe S, Montesinos J, Guerri C. LPS or ethanol triggers clathrin- and rafts/ caveolae-dependent endocytosis of TLR4 in cortical astrocytes. J Neurochem 2014;129:448-62. DOI:10.1111/ jnc. 12639

34. Fernandez-Lizarbe S, Pascual M, Guerri C. Critical role of TLR4 response in the activation of microglia induced by ethanol. J Immunol Baltim Md 2009;183:4733-44. DOI:10.4049/jimmunol.0803590

35. Alfonso-Loeches S, Ureña-Peralta JR, Morillo-Bargues MJ, Oliver-De La Cruz J, Guerri C. Role of mitochondria
ROS generation in ethanol-induced NLRP3 inflammasome activation and cell death in astroglial cells. Front Cell Neurosci 2014;8:216. DOI:10.3389/fncel.2014.00216

36. Alfonso-Loeches S, Guerri C. Molecular and behavioral aspects of the actions of alcohol on the adult and developing brain. Crit Rev Clin Lab Sci 2011;48:19-47. DOI:10. 3109/10408363.2011.580567

37. Alfonso-Loeches S, Pascual M, Gómez-Pinedo U, Pascual-Lucas M, Renau-Piqueras J, Guerri C. Toll-like receptor 4 participates in the myelin disruptions associated with chronic alcohol abuse. Glia 2012;60:948-64. DOI:10.1002/glia.22327

38. Alfonso-Loeches S, Pascual M, Guerri C. Gender differences in alcohol-induced neurotoxicity and brain damage. Toxicology 2013;311:27-34. DOI:10.1016/j. tox.2013.03.001

39. Alfonso-Loeches S, Pascual-Lucas M, Blanco AM, Sanchez-Vera I, Guerri C. Pivotal role of TLR4 receptors in alcohol-induced neuroinflammation and brain damage. J Neurosci J Soc Neurosci 2010;30:8285-95. DOI:10.1523/JNEUROSCI.0976-10.2010

40. Alfonso-Loeches S, Ureña-Peralta J, Morillo-Bargues MJ, Gómez-Pinedo U, Guerri C. Ethanol-Induced TLR4/ NLRP3 Neuroinflammatory Response in Microglial Cells Promotes Leukocyte Infiltration Across the BBB. Neurochem Res 2016;41:193-209. DOI:10.1007/s11064015-1760-5

41. Pla A, Pascual M, Renau-Piqueras J, Guerri C. TLR4 mediates the impairment of ubiquitin-proteasome and autophagy-lysosome pathways induced by ethanol treatment in brain. Cell Death Dis 2014;5:e1066. [doi:10.1038/cddis.2014.46.]

42. Zou J, Vetreno RP, Crews FT. ATP-P2X7 receptor signaling controls basal and TNF $\alpha$-stimulated glial cell proliferation. Glia 2012;60:661-73. [DOI: 10.1002/glia.22302]

43. Montesinos J, Alfonso-Loeches S, Guerri C. Impact of the Innate Immune Response in the Actions of Ethanol on the Central Nervous System. Alcohol Clin Exp Res 2016;40:2260-70. [DOI:10.1111/acer.13208]

44. Montesinos J, Pascual M, Rodríguez-Arias M, Miñarro J, Guerri C. Involvement of TLR4 in the long-term epigenetic changes, rewarding and anxiety effects induced by intermittent ethanol treatment in adolescence. Brain Behav Immun 2016;53:159-171. DOI:10.1016/j. bbi.2015.12.006

45. Vetreno RP, Crews FT. Current hypotheses on the mechanisms of alcoholism. Handb Clin Neurol 2014;125:477- 
97. DOI:10.1016/B978-0-444-62619-6.00027-6

46. Crews FT, Vetreno RP. Neuroimmune basis of alcoholic brain damage. Int Rev Neurobiol 2014;118:315-57. DOI:10.1016/B978-0-12-801284-0.00010-5

47. Rubio-Araiz A, Porcu F, Pérez-Hernández M, GarcíaGutiérrez MS, Aracil-Fernández MA, Gutierrez-López $\mathrm{MD}$, et al. Disruption of blood-brain barrier integrity in postmortem alcoholic brain: preclinical evidence of TLR4 involvement from a binge-like drinking model. Addict Biol 2017;22:1103-16. DOI:10.1111/adb.12376

48. Pruett SB, Zheng Q, Fan R, Matthews K, Schwab C. Ethanol suppresses cytokine responses induced through Toll-like receptors as well as innate resistance to Escherichia coli in a mouse model for binge drinking. $\mathrm{Al}$ cohol Fayettev N 2004;33:147-55. DOI:10.1016/j.alcohol.2004.08.001

49. Kuwata H, Watanabe Y, Miyoshi H, Yamamoto M, Kaisho T, Takeda K, et al. IL-10-inducible Bcl-3 negatively regulates LPS-induced TNF-alpha production in macrophages. Blood 2003;102:4123-4129. DOI:10.1182/ blood-2003-04-1228

50. Deak T, Okrainets A, Doremus-Fitzwater TL. Mechanisms of stress-dependent neuroinflammation and their implications for understanding consequences of alcohol exposure. Neural-Immune Interact. Brain Funct. Alcohol Relat. Disord., Springer; 2013, p. 133-66.

51. Barr T, Helms C, Grant K, Messaoudi I. Opposing effects of alcohol on the immune system. Prog Neuropsychopharmacol Biol Psychiatry 2016;65:242-51. DOI:10.1016/j.pnpbp.2015.09.001

52. Mandrekar P, Bala S, Catalano D, Kodys K, Szabo G. The opposite effects of acute and chronic alcohol on lipopolysaccharide-induced inflammation are linked to IRAK$\mathrm{M}$ in human monocytes. J Immunol Baltim Md 1950 2009;183:1320-7. DOI:10.4049/jimmunol.0803206

53. Laso FJ, Vaquero JM, Almeida J, Marcos M, Orfao A. Production of inflammatory cytokines by peripheral blood monocytes in chronic alcoholism: relationship with ethanol intake and liver disease. Cytometry B Clin Cytom 2007;72:408-15. DOI:10.1002/cyto.b.20169

54. Burke HM, Davis MC, Otte C, Mohr DC. Depression and cortisol responses to psychological stress: a metaanalysis. Psychoneuroendocrinology 2005;30:846-56. DOI:10.1016/j.psyneuen.2005.02.010

55. Sinha R, Fox HC, Hong K-IA, Hansen J, Tuit K, Kreek MJ. Effects of adrenal sensitivity, stress- and cue-induced craving, and anxiety on subsequent alcohol relapse and treatment outcomes. Arch Gen Psychiatry 2011;68:94252. DOI:10.1001/archgenpsychiatry.2011.49

56. Breese GR, Overstreet DH, Knapp DJ, Navarro M. Prior multiple ethanol withdrawals enhance stress-induced anxiety-like behavior: inhibition by CRF1- and benzodiazepine-receptor antagonists and a 5-HT1a-receptor agonist. Am Coll Neuropsychopharmacol 2005;30:16621669. DOI:10.1038/sj.npp.1300706

57. Alonso R, Griebel G, Pavone G, Stemmelin J, Le Fur G, Soubrié P. Blockade of CRF1 or V(1b) receptors reverses stress-induced suppression of neurogenesis in a mouse model of depression. Mol Psychiatry 2004;9:278-286, 224. DOI:10.1038/sj.mp.4001464

58. Badawy AA-B, Doughrty DM, Marsh-Richard DM, Steptoe A. Activation of liver tryptophan pyrrolase mediates the decrease in tryptophan availability to the brain after acute alcohol consumption by normal subjects. Alcohol Alcohol Oxf 2009;44:267-271. DOI:10.1093/alcalc/ agp005

59. Branchey L, Branchey M, Shaw S, Lieber CS. Relationship between changes in plasma amino acids and depression in alcoholic patients. Am J Psychiatry 1984;141:1212-1215. DOI:10.1176/ajp.141.10.1212

60. Dantzer R, O'Connor JC, Lawson MA, Kelley KW. Inflammation-associated depression: from serotonin to kynurenine. Psychoneuroendocrinology 2011;36:42636. DOI:10.1016/j.psyneuen.2010.09.012

61. O'Connor JC, André C, Wang Y, Lawson MA, Szegedi $\mathrm{SS}$, Lestage J, et al. Interferon-gamma and tumor necrosis factor-alpha mediate the upregulation of indoleamine 2,3-dioxygenase and the induction of depressivelike behavior in mice in response to bacillus CalmetteGuerin. J Neurosci Off J Soc Neurosci 2009;29:4200-9. DOI:10.1523/JNEUROSCI.5032-08.2009

62. Cui C, Grandison L, Noronha A. Neural-immune interactions in brain function and alcohol related disorders. Springer Science \& Business Media; 2012.

63. Maes M, Bosmans E, Suy E, Vandervorst C, De Jonckheere C, Raus J. Immune disturbances during major depression: upregulated expression of interleukin-2 receptors. Neuropsychobiology 1990;24:115-120.

64. Smith RS. The macrophage theory of depression. Med Hypotheses 1991;35:298-306.

65. Maes M, Yirmyia R, Noraberg J, Brene S, Hibbeln J, Perini $\mathrm{G}$, et al. The inflammatory and neurodegenerative (I\&ND) hypothesis of depression: leads for future research and new drug developments in depression. Me- 
tab Brain Dis 2009;24:27-53. DOI:10.1007/s11011-0089118-1

66. Crews FT, Vetreno RP. Addiction, adolescence, and innate immune gene induction. Front Psychiatry 2011;2:19. DOI:10.3389/fpsyt.2011.00019

67. Ceccanti M, Coriale G, Hamilton D, Carito V, Coccurello R, Scalese B, et al. Virtual Morris task responses in individuals in an abstinence phase from alcohol. Can J Physiol Pharmacol 2017. DOI:10.1139/cjpp-2017-0013

68. Ceccanti M, Hamilton D, Coriale G, Carito V, Aloe L, Chaldakov $\mathrm{G}$, et al. Spatial learning in men undergoing alcohol detoxification. Physiol Behav 2015;149:324-30. DOI:10.1016/j.physbeh.2015.06.034

69. Zhao C, Teng EM, Summers RG, Ming G-L, Gage FH. Distinct morphological stages of dentate granule neuron maturation in the adult mouse hippocampus. $J$ Neurosci Off J Soc Neurosci 2006;26:3-11. [doi:10.1523/JNEUROSCI.3648-05.2006.]

70. Altman J, Das GD. Autoradiographic and histological evidence of postnatal hippocampal neurogenesis in rats. $J$ Comp Neurol 1965;124:319-35.

71. Stanton PK. LTD, LTP, and the sliding threshold for longterm synaptic plasticity. Hippocampus 1996;6:35-42. DOI:10.1002/(SICI)1098-1063(1996)6:1<35::AIDHIPO7>3.0.CO;2-6

72. Maggio N, Shavit-Stein E, Dori A, Blatt I, Chapman J. Prolonged systemic inflammation persistently modifies synaptic plasticity in the hippocampus: modulation by the stress hormones. Front Mol Neurosci 2013;6:46. DOI:10.3389/fnmol.2013.00046

73. Zou J, Crews F. Induction of innate immune gene expression cascades in brain slice cultures by ethanol: key role of NF-kB and proinflammatory cytokines. Alcohol Clin Exp Res 2010;34:777-789. DOI:10.1111/j.15300277.2010.01150.x

74. Nixon K, Crews FT. Binge ethanol exposure decreases neurogenesis in adult rat hippocampus. $J$ Neurochem 2002;83:1087-93. DOI: 10.1046/j.14714159.2002.01214.x

75. Crews FT, Bechara R, Brown LA, Guidot DM, Mandrekar P, Oak S, et al. Cytokines and alcohol. Alcohol Clin Exp Res 2006;30:720-30. DOI:10.1111/j.15300277.2006.00084.x

76. McClain JA, Morris SA, Deeny MA, Marshall SA, Hayes DM, Kiser ZM, et al. Adolescent binge alcohol exposure induces long-lasting partial activation of microglia. Brain Behav Immun 2011;25 Suppl 1:S120-128.

\section{DOI:10.1016/j.bbi.2011.01.006}

77. Gonzalez-Perez O, Ramos-Remus C, Garcia-Estrada J, Luquin S. Prednisone induces anxiety and glial cerebral changes in rats. $J$ Rheumatol 2001;28:2529-2534.

78. Blednov YA, Bergeson SE, Walker D, Ferreira VMM, Kuziel WA, Harris RA. Perturbation of chemokine networks by gene deletion alters the reinforcing actions of ethanol. Behav Brain Res 2005;165:110-125. DOI:10.1016/j.bbr.2005.06.026

79. June HL, Liu J, Warnock KT, Bell KA, Balan I, Bollino $\mathrm{D}$, et al. CRF-amplified neuronal TLR4/MCP-1 signaling regulates alcohol self-administration. Neuropsychopharmacol Off Publ Am Coll Neuropsychopharmacol 2015;40:1549-1559. DOI:10.1038/npp.2015.4

80. Montesinos J, Pascual M, Pla A, Maldonado C, Rodríguez-Arias M, Miñarro J, et al. TLR4 elimination prevents synaptic and myelin alterations and long-term cognitive dysfunctions in adolescent mice with intermittent ethanol treatment. Brain Behav Immun 2015;45:233-44. DOI:10.1016/j.bbi.2014.11.015

81. Pascual M, Baliño P, Alfonso-Loeches S, Aragón CMG, Guerri C. Impact of TLR4 on behavioral and cognitive dysfunctions associated with alcohol-induced neuroinflammatory damage. Brain Behav Immun 2011;25(Suppl 1):S80-91. DOI:10.1016/j.bbi.2011.02.012

82. Blednov YA, Ponomarev I, Geil C, Bergeson S, Koob GF, Harris RA. Neuroimmune regulation of alcohol consumption: behavioral validation of genes obtained from genomic studies. Addict Biol 2012;17:108-20. DOI:10.1111/j.1369-1600.2010.00284.x

83. Achur RN, Freeman WM, Vrana KE. Circulating cytokines as biomarkers of alcohol abuse and alcoholism. $J$ Neuroimmune Pharmacol Off J Soc NeuroImmune Pharmacol 2010;5:83-91. DOI:10.1007/s11481-009-9185-z

84. Kissack JC, Bishop J, Roper AL. Ethylglucuronide as a biomarker for ethanol detection. Pharmacotherapy 2008;28:769-781. DOI:10.1592/phco.28.6.769

85. Ferraguti G, Ciolli P, Carito V, Battagliese G, Mancinelli $\mathrm{R}$, Ciafrè $\mathrm{S}$, et al. Ethylglucuronide in the urine as a marker of alcohol consumption during pregnancy: Comparison with four alcohol screening questionnaires. Toxicol Lett 2017;275:49-56. DOI:10.1016/j.toxlet.2017.04.016

86. Taracha E, Habrat B, Woźniak P, Walkowiak J, Szukalski B. The activity of beta-hexosaminidase (uHex) and gamma-glutamyl-transferase (uGGT) in urine as non-invasive markers of chronic alcohol abuse: I. Alcohol-dependent subjects. World J Biol Psychiatry Off J World Fed Soc 
Biol Psychiatry 2001;2:184-9.

DOI: $10.3109 / 15622970109026807$

87. Niemelä O. Biomarker-based approaches for assessing alcohol use disorders. Int $J$ Environ Res Public Health 2016;13:166. DOI:10.3390/ijerph13020166

88. Koch H, Meerkerk G-J, Zaat JOM, Ham MF, Scholten RJPM, Assendelft WJJ. Accuracy of carbohydrate-deficient transferrin in the detection of excessive alcohol consumption: a systematic review. Alcohol Alcohol Oxf Oxfs 2004;39:75-85.

89. Golka K, Wiese A. Carbohydrate-deficient transferrin (CDT)--a biomarker for long-term alcohol consumption. J Toxicol Environ Health B Crit Rev 2004;7:319-337. DOI:10.1080/10937400490432400

90. Helander A, Eriksson CJP, WHO/ISBRA Study on State and Trait Markers ofAlcohol Use and Dependence Investigators. Laboratory tests for acute alcohol consumption: results of the WHO/ISBRA Study on State and Trait Markers of Alcohol Use and Dependence. Alcohol Clin Exp Res 2002;26:1070-1077. DOI: 10.1111/j.15300277.2002.tb02641.x

91. Comasco E, Nordquist N, Leppert J, Oreland L, Kronstrand R, Alling C, et al. Adolescent alcohol consumption: biomarkers PEth and FAEE in relation to interview and questionnaire data. $J$ Stud Alcohol Drugs 2009;70:797-804. DOI:10.15288/jsad.2009.70.797

92. Björkqvist M, Ohlsson M, Minthon L, Hansson O. Evaluation of a previously suggested plasma biomarker panel to identify Alzheimer's disease. PloS One 2012;7:e29868. DOI:10.1371/journal.pone.0029868

93. An L, Wang X, Cederbaum AI. Cytokines in alcoholic liver disease. Arch Toxicol 2012;86:1337-1348. DOI:10.1007/s00204-012-0814-6

94. Gonzalez-Quintela A, Alende R, Gude F, Campos J, Rey J, Meijide LM, et al. Serum levels of immunoglobulins (IgG, IgA, IgM) in a general adult population and their relationship with alcohol consumption, smoking and common metabolic abnormalities. Clin Exp Immunol 2008;151:42-50. DOI:10.1111/j.13652249.2007.03545.x

95. Gonzalez-Quintela A, Garrido M, Gude F, Campos $\mathrm{J}$, Linneberg A, Lojo S, et al. Sensitization to crossreactive carbohydrate determinants in relation to alcohol consumption. Clin Exp Allergy 2008;38:152-60. DOI:10.1111/j.1365-2222.2007.02863.x

96. Carito V, Ceccanti M, Ferraguti G, Coccurello R, Ciafrè $\mathrm{S}$, Tirassa $\mathrm{P}$, et al. NGF and BDNF alterations by prenatal alcohol exposure. Curr Neuropharmacol 2017. DOI:10.2 174/1570159X15666170825101308

97. Ceccanti M, De Nicolo S, Mancinelli R, Chaldakov G, Carito V, Ceccanti M, et al. NGF and BDNF longterm variations in the thyroid, testis and adrenal glands of a mouse model of fetal alcohol spectrum disorders. Ann Ist Super Sanita 2013;49:383-90. DOI: 10.4415/ ann_13_04_11

98. Ceccanti M, Mancinelli R, Tirassa P, Laviola G, Rossi S, Romeo $\mathrm{M}$, et al. Early exposure to ethanol or red wine and long-lasting effects in aged mice. A study on nerve growth factor, brain-derived neurotrophic factor, hepatocyte growth factor, and vascular endothelial growth factor. Neurobiol Aging 2012;33:359-367. DOI: 10.1016/j. neurobiolaging.2010.03.005

99. Ceccanti M, Carito V, Vitali M, Iannuzzi S, Tarani L, De Nicolò $\mathrm{S}$, et al. Serum BDNF and NGF modulation by olive polyphenols in alcoholics during withdrawal. $J$ Alcohol Drug Depend 2015;3:1-6. DOI:10.4172/23296488.1000214]

100. Ceccanti M, Coccurello R, Carito V, Ciafrè S, Ferraguti G, Giacovazzo G, et al. Paternal alcohol exposure in mice alters brain NGF and BDNF and increases ethanol-elicited preference in male offspring. Addict Biol 2016;21:776-787. DOI:10.1111/adb.12255

101. De Nicolo S, Tarani L, Ceccanti M, Maldini M, Natella F, Vania A, et al. Effects of olive polyphenols administration on nerve growth factor and brain-derived neurotrophic factor in the mouse brain. Nutrition 2013;29:681-687. DOI: 10.1016/j.nut.2012.11.007

102. Fiore M, Mancinelli R, Aloe L, Laviola G, Sornelli F, Vitali $\mathrm{M}$, et al. Hepatocyte growth factor, vascular endothelial growth factor, glial cell-derived neurotrophic factor and nerve growth factor are differentially affected by early chronic ethanol or red wine intake. Toxicol Lett 2009;188:208-13. DOI: 10.1016/j.toxlet.2009.04.013

103. Aloe L. Alcohol intake during prenatal life affects neuroimmune mediators and brain neurogenesis. Ann Ist Super Sanita 2006;42:17-21.

104. De Simone R, Aloe L. Influence of ethanol consumption on brain nerve growth factor and its target cells in developing and adult rodents. Ann Ist Super Sanita 1993;29:179-183.

105. Aloe L, Bracci-Laudiero L, Tirassa P. The effect of chronic ethanol intake on brain NGF level and on NGF-target tissues of adult mice. Drug Alcohol Depend 1993;31:159167. DOI:10.1016/0376-8716(93)90068-2 
106. Aloe L, Tirassa P. The effect of long-term alcohol intake on brain NGF-target cells of aged rats. Alcohol 1992;9:299-304. DOI:10.1016/0741-8329(92)90070-Q

107. Aloe L, Tuveri MA, Guerra G, Pinna L, Tirassa P, Micera $\mathrm{A}$, et al. Changes in human plasma nerve growth factor level after chronic alcohol consumption and withdrawal. Alcohol Clin Exp Res 1996;20:462-465. DOI: 10.1111/ j.1530-0277.1996.tb01076.x

108. Vuorela P, Sarkola T, Alfthan H, Halmesmäki E. Hepatocyte growth factor, epidermal growth factor, and placenta growth factor concentrations in peripheral blood of pregnant women with alcohol abuse. Alcohol Clin Exp Res 2002;26:682-687. DOI: 10.1111/j.1530-0277.2002. tb02591.x

109. Kocerha J, Faghihi MA, Lopez-Toledano MA, Huang J, Ramsey AJ, Caron MG, et al. MicroRNA-219 modulates NMDA receptor-mediated neurobehavioral dysfunction. Proc Natl Acad Sci USA 2009;106:3507-3512. DOI:10.1073/pnas.0805854106

110. Kocerha J, Kauppinen S, Wahlestedt C. microRNAs in CNS disorders. Neuromolecular Med 2009;11:162-172. DOI:10.1007/s12017-009-8066-1

111. Lippai D, Bala S, Petrasek J, Csak T, Levin I, Kurt-Jones EA, et al. Alcohol-induced IL-1 $\beta$ in the brain is mediated by NLRP3/ASC inflammasome activation that amplifies neuroinflammation. J Leukoc Biol 2013;94:171-82. DOI:10.1189/jlb.1212659

112. Zhang Y, Wei G, Di Z, Zhao Q. miR-339-5p inhibits alcohol-induced brain inflammation through regulating NF-кB pathway. Biochem Biophys Res Commun 2014;452:450-456. DOI:10.1016/j.bbrc.2014.08.092

113. Vetreno RP, Yaxley R, Paniagua B, Johnson GA, Crews FT. Adult rat cortical thickness changes across age and following adolescent intermittent ethanol treatment. $\mathrm{Ad}$ dict Biol 2017;22:712-723. DOI: 10.1111/adb

114. Risher ML, Sexton HG, Risher WC, Wilson WA, Fleming RL, Madison RD, et al. Adolescent intermittent alcohol exposure: dysregulation of thrombospondins and synapse formation are associated with decreased neuronal density in the adult hippocampus. Alcohol Clin Exp Res 2015;39:2403-2413. DOI: 10.1111/acer.12913

115. Spear LP. The adolescent brain and age-related behavioral manifestations. Neurosci Biobehav Rev 2000;24:417463.403-2413. [doi.org/10.1016/S0149-7634(00)000142

116. Spear LP. Adolescents and alcohol. Curr Dir Psychol Sci 2013;22:152-157. DOI: 10.1177/0963721412472192
117. Luna B, Marek S, Larsen B, Tervo-Clemmens B, Chahal R. An integrative model of the maturation of cognitive control. Annu Rev Neurosci 2015;38:151-170. DOI: 10.1146/annurev-neuro-071714-034054

118. Grant BF. The impact of a family history of alcoholism on the relationship between age at onset of alcohol use and DSM-IV alcohol dependence: results from the National Longitudinal Alcohol Epidemiologic Survey. Alcohol Health Res World 1998;22: 144-147.

119. Gao F, Liu Z, Ren W, Jiang W. Acute lipopolysaccharide exposure facilitates epileptiform activity via enhanced excitatory synaptic transmission and neuronal excitability in vitro. Neuropsychiatr Dis Treat 2014;10:1489-1495. DOI: 10.2147/NDT.S65695

120. Guerri C, Pascual M. Mechanisms involved in the neurotoxic, cognitive, and neurobehavioral effects of alcohol consumption during adolescence. Alcohol 2010;44:1526. DOI: 10.1016/j.alcohol.2009.10.003

121. Pascual M, Blanco AM, Cauli O, Minarro J, Guerri C. Intermittent ethanol exposure induces inflammatory brain damage and causes long-term behavioural alterations in adolescent rats. Eur J Neurosci 2007;25:541-550. DOI: 10.1111/j.1460-9568.2006.05298.x

122. Ward RJ, Colivicchi MA, Allen R, Schol F, Lallemand F, de Witte P, Ballini C, Corte LD, Dexter D. Neuro-inflammation induced in the hippocampus of 'binge drinking' rats may be mediated by elevated extracellular glutamate content. J Neurochem 2009;111:1119-1128. DOI: 10.1111/j.1471-4159.2009.06389.x

123. Vetreno RP, Crews FT. Adolescent binge drinking increases expression of the danger signal receptor agonist HMGB1 and Toll-like receptors in the adult prefrontal cortex. Neuroscience 2012;226:475-488. [doi: 10.1016/j. neuroscience.2012.08.046]

124. Zou JY, Crews FT. Release of neuronal HMGB1 by ethanol through decreased HDAC activity activates brain neuroimmune signaling. PLoS One 2014;9:e87915. DOI: 10.1371/journal.pone.0087915

125. Cantacorps L, Alfonso-Loeches S, Moscoso-Castro M, Cuitavi J, Gracia-Rubio I, López-Arnau R, et al. Maternal alcohol binge drinking induces persistent neuroinflammation associated with myelin damage and behavioural dysfunctions in offspring mice. Neuropharmacology 2017;123:368-384. DOI: 10.1016/j.neuropharm.2017.05.034

126. Agrawal RG, Hewetson A, George CM, Syapin PJ, Bergeson SE Minocycline reduces ethanol drinking. 
Brain Behav Immun 2011;25(Suppl 1): S165-S169. DOI: 10.1016/j.bbi.2011.03.002

127. Wu Y, Lousberg EL, Moldenhauer LM, Hayball JD, Robertson SA, Coller JK, Watkins LR, Somogyi AA, Hutchinson MR. Attenuation of microglial and IL-1 signaling protects mice from acute alcohol-induced sedation and/ or motor impairment. Brain Behav Immun 2011;25(Suppl 1):S155-S164. DOI: 10.1016/j.bbi.2011.01.012

128. Whitman BA, Knapp DJ, Werner DF, Crews FT, Breese GR. The cytokine mRNA increase induced by withdrawal from chronic ethanol in the sterile environment of brain is mediated by CRF and HMGB1 release. Alcohol Clin Exp Res 2012;37:2086-2097. DOI: 10.1111/acer.12189

129. Anton M, Alen F, Gomez de Heras R, Serrano A, Pavon FJ, Leza JC, et al. Oleoylethanolamide prevents neuroimmune HMGB1/TLR4/NF-kB danger signaling in rat frontal cortex and depressive-like behavior induced by ethanol binge administration. Addict Biol 2017;22:724741. DOI: $10.1111 / \mathrm{adb} .12365$.

130. Carito V, Ceccanti M, Tarani L, Ferraguti G, Chaldakov GN, Fiore M. Neurotrophins' modulation by olive polyphenols. Curr Med Chem 2016;23:3189-3197. DOI: 10.2 174/0929867323666160627104022

131. Carito V, Ceccanti M, Cestari V, Natella F, Bello C, Coccurello R, Mancinelli R, Fiore M. Olive polyphenol effects in a mouse model of chronic ethanol addiction. $\mathrm{Nu}$ trition 2017;33:65-69. DOI: 10.1016/j.nut.2016.08.014.

\section{ABBREVIATIONS}

\begin{tabular}{|l|l|}
\hline 5HTOL & 5-hydroxytryptophol \\
\hline ACTH & Adrenocorticotropic hormone \\
\hline AD & Alzheimer's disease \\
\hline ALT & Alanine aminotrasferase \\
\hline AP-1 & Activator protein 1 \\
\hline AST & Aspartate aminotransferase \\
\hline BBB & Blood-brain barrier \\
\hline BDNF & Brain-derived neurotrophic factor \\
\hline CDT & Carbohydrate-deficient trasferrin \\
\hline CeA & Central nucleus of the amygdala \\
\hline CNS & Central nervous system \\
\hline COX2 & Cytochrome c oxidase subunit 2 \\
\hline CREB & cAMP response element-binding protein \\
\hline CRF & Corticotropin-releasing factor \\
\hline
\end{tabular}

\begin{tabular}{|c|c|}
\hline DAMPs & Damage-associated molecular patterns \\
\hline EGF & Epidermal growth factor \\
\hline EtG & Ethylglucuronide \\
\hline FASD & Fetal alcohol spectrum disorders \\
\hline FosB & $\begin{array}{l}\text { FBJ murine osteosarcoma viral oncogene homolog } \\
\text { B }\end{array}$ \\
\hline GGT & Gamma-glutamyltransferase \\
\hline HMGB1 & High mobility group box 1 \\
\hline HPA & Hypothalamic-pituitary-adrenal axis \\
\hline IDO & Indoleamine-pyrrole 2,3-dioxygenase \\
\hline IL & Interleukins \\
\hline iNOS & Inducible Nitric oxide synthases \\
\hline LPS & Lipopolysaccharide endotoxin \\
\hline LTP & Long-term potentiation \\
\hline MAPK & Mitogen-activated protein kinase \\
\hline MCP-1 & Monocyte chemoattractant protein 1 \\
\hline $\mathrm{MCV}$ & Mean corpuscular volume \\
\hline MHC & Major histocompatibility complex \\
\hline $\operatorname{miR}$ & microRNA \\
\hline $\mathrm{mPFC}$ & Medial prefrontal cortex medial prefrontal cortex \\
\hline mROS & Mitochondrial Reactive oxygen species \\
\hline NAc & Nucleus accumbens \\
\hline NF-kB & $\begin{array}{l}\text { Nuclear factor kappa-light-chain-enhancer of } \\
\text { activated B cells }\end{array}$ \\
\hline NLR & $\begin{array}{l}\text { Nucleotide-binding oligomerization domain-like } \\
\text { receptors }\end{array}$ \\
\hline NLRP & NLR family pyrin domain containing 1 \\
\hline NMDA & N-Methyl-D-aspartic acid \\
\hline PAMPs & Pathogen-associated molecular patterns \\
\hline $\mathrm{PD}$ & Parkinson's disease \\
\hline PEth & Phosphatidylethanol \\
\hline PGF & Placental growth factor \\
\hline Pro-IL & Interleukin precursor \\
\hline PRRs & Pattern recognition receptors \\
\hline RAGE & Receptor for advanced glycation endproduct \\
\hline siRNA & Small interfering RNA \\
\hline TDO & Tryptophan 2,3-dioxygenase \\
\hline TLR & Toll-like receptors \\
\hline TNF-a & Tumor necrosis factor alpha \\
\hline VTA & Ventral tegmental area \\
\hline
\end{tabular}

